\title{
The colloidal tool-box approach for fuel cell catalysts: utilizing graphitized carbon supports
}

Alessandro Zana ${ }^{\mathrm{a}}$, Tom Vosch ${ }^{\mathrm{a}}$ and Matthias Arenz $\mathrm{z}^{\mathrm{a}, \mathrm{b} *}$

${ }^{a}$ Nano-Science Center, Department of Chemistry, University of Copenhagen, Universitetsparken 5, DK-2100 Copenhagen $\varnothing$, Denmark

${ }^{b}$ Department of Chemistry and Biochemistry, University of Bern, Freiestrasse 3, 3012 Bern, Switzerland

*corresponding author: matthias.arenz@dcb.unibe.ch

\begin{abstract}
In the presented study we apply the "tool-box" approach for studying colloidal Pt nanoclusters as building blocks for polymer electrolyte membrane fuel cells (PEMFCs) catalysts utilizing graphitized carbon as support. In line with previous studies we concentrate on the influence of the carbon support on the degradation of PEMFC catalysts. It is demonstrated that a mild etching of the graphitized carbon support can lead to an improved stability under accelerated stress tests targeting carbon corrosion.
\end{abstract}

\section{Keywords}

Polymer electrolyte membrane fuel cells; Cathode catalyst layer; Catalyst supports; Oxygen reduction reaction 


\section{Introduction}

Colloidal metal nanoclusters stabilized by simple ions are promising building blocks for supported catalysts $[1,2]$. In recent years we deployed colloidal nanoclusters for the systematic investigation of Pt based catalysts for polymer electrolyte membrane fuel cells (PEMFCs) and coined the term "tool-box" synthesis [3-8]. The basic concept of the tool-box synthesis is the ability to systematically change individual parameters of the catalyst, while the other parameters remain constant. The synthesis basically consists of two steps. First a colloidal "mother" suspension of Pt or Pt-alloy nanoparticles (NPs) is prepared. The NPs are stabilized by simple, non-strongly binding ions $[1,9]$, which can easily be removed without changing the NPs, i.e. without the typical applied heating steps, ozone treatment etc. [10-16]. Then in the second step, the NPs are attached to a high surface area support by a simple drying procedure, which does not affect the NP or the support properties. Thus the synthesis allows us for example to change the Pt loading on a carbon support at constant, well-defined particle size $[3,5]$, or to obtain a constant loading on different carbon supports [7]. Even though the obtained catalysts perform comparable to industrial samples, the main purpose of such studies is to bridge the gap between basic and applied research. That is to perform "use inspired basic research".

In the last decade most research concerning fuel cell catalysts was focused on the development of new, highly active catalytic materials [17]. In light of the obtained improvements - especially in the field of non-precious metal catalysts [18], "plain" activity optimization may no longer be the most important goal [19]. Instead the aim needs to be to concurrently increase durability and power density (for a given amount of Pt). In our research group, in recent years we therefore focused on fuel cell catalyst stability. One of the main limitations concerning the stability of conventional high surface area (HSA) Pt/C catalysts is the stability of Pt NPs as well as the corrosion of the carbon support [20-26]. Efforts to exchange the carbon support by more stable, oxide based supports may 
exhibit some improvements in half-cell tests [27], but the excellent properties of carbon (for example its porosity) are more decisive for the performance in membrane electrode assemblies or fuel cell stacks.

The presented work therefore focuses on the characterization of catalysts supported on graphitized carbon blacks (GCB). The improved corrosion resistance of GCBs as compared to standard CBs (i.e. Vulcan XC72R) is long known and makes them an interesting support for Pt NPs [28]. However, due to the less defective nature of GCBs the challenge is to reach a high dispersion of Pt during the synthesis of Pt/GCB. In conventional synthesis, due to the small amount of agglomeration sites, the formation of large particles is favored. On the other hand, creating surface sites by etching of the carbon poses the risk of destroying the carbon structure and inducing surface sites for carbon corrosion. Here we investigate a possible strategy to circumvent these difficulties. Applying our "tool-box" synthesis approach we investigate GCBs that has been mildly etched before particle attachment. The goal is to generate just the right amount of anchoring sites for Pt NPs, but without destroying the ordered carbon structure.

\section{Experimental}

\section{1 - Colloidal synthesis approach of carbon supported Pt nanoparticles}

The catalysts used in this work were in house synthesized based on the original recipe of colloidal Pt nanoclusters by Wang et al. [9] as described in our previous work [4]. As mentioned above, first a colloidal "mother" suspension of Pt NPs with a narrow size distribution and an average particle size of about $2 \mathrm{~nm}$ was synthesized via an ethylene glycol route (EG). Then, in the second step, different catalysts were made from the same mother solution by washing, re-dispersing and drying Pt NPs onto various carbon supports. As carbon supports Vulcan XC72R (Cabot Corporation, in the following named Vulcan), GCB and GCB treated in $\mathrm{H}_{2} \mathrm{O}_{2}\left(\mathrm{GCB} \mathrm{H}_{2} \mathrm{O}_{2}\right)$ were used. The GCB 
support was provided by Umicore AG \& Co KG. It was obtained by graphitizing Ketjenblack EC600JD carbon support (Akzo Nobel) in an inert atmosphere at $3200{ }^{\circ} \mathrm{C}$.

In the following the individual steps of the catalyst synthesis are shortly described. For a more detailed description of the EG synthesis and the so called "tool box"approach see Refs. [4, 9]. The colloidal solution containing Pt NPs was synthesized by mixing a solution of ethylene glycol and $\mathrm{NaOH}$ with an ethylene glycol (EG) solution of $\mathrm{H}_{2} \mathrm{PtCl}_{6} \mathrm{H}_{2} \mathrm{O}$ in EG. A typical recipe, the one used here, is to use $50 \mathrm{~mL}$ of $0.4 \mathrm{M}$ in $\mathrm{NaOH}-\mathrm{EG}$ mixed with $1.0 \mathrm{~g} \mathrm{H}_{2} \mathrm{PtCl}_{6} \mathrm{H}_{2} \mathrm{O}$ precursor dissolved in $50 \mathrm{~mL}$ EG. Alternatively also smaller amounts can be prepared when keeping the concentrations and ratios constant. The yellowish platinum hydroxide or oxide colloidal solution in EG was subsequently heated to $160{ }^{\circ} \mathrm{C}$ for $3 \mathrm{~h}$ under reflux in an $\mathrm{Ar}$ atmosphere. During heating a blackishbrown homogeneous metal particle colloidal suspension with a Pt concentration of $4 \mathrm{~g}_{\mathrm{P}} / \mathrm{l}_{\mathrm{EG}}$ forms. Alternative to an oil heating bath, a microwave reactor can be applied [29], which renders the particle synthesis extremely fast. The obtained particle suspension is stabilized by the adsorption of simple ions and can be used as mother suspension for different catalysts with identical Pt NPs. The size of the thus synthesized Pt NPs in EG can be checked by small angle X-ray scattering (SAXS) and is very reproducible around $2 \mathrm{~nm}$ in diameter exhibiting a narrow size distribution.

To support the Pt NPs onto the carbon powder $1 \mathrm{M} \mathrm{HCl}$ was added to the colloidal NP solution in a ratio of ca. 2:1 (ml/ml; HCl/NP solution) for precipitation. The solution was centrifuged (4000 rpm, $6 \mathrm{~min}$ ) and the supernatant solvent discarded. This procedure was repeated before re-dispersing the NPs in acetone. Finally, the as-synthesized Pt NPs were deposited onto the different carbon supports by mixing the NPs suspension (in acetone) with carbon mixed in $3 \mathrm{~mL}$ of acetone and sonicating for $1 \mathrm{~h}$. The catalyst samples were prepared with two different nominal Pt loadings; i.e. 30 wt.\% Pt/Vulcan as well as 10 wt.\% Pt/GCB and 10 wt.\% Pt/GCB $\mathrm{H}_{2} \mathrm{O}_{2}$. Finally the catalyst is 
dried. Efforts to increase the Pt loading of the GCB supports without loss in surface area were not successful.

The actual Pt loading of the catalysts was determined by using inductively coupled plasma mass spectrometry (ICP-MS) measurements. For this, the catalysts were dissolved in aqua regia (freshly mixed cc. $\mathrm{HNO}_{3}$ and $\mathrm{cc} . \mathrm{HCl}$ in a volumetric ratio of $1: 3$, respectively). The concentration of platinum in the diluted aqua regia solution was analyzed by ICP-MS (NexION 300X, Perkin Elmer) through a Meinhard quartz nebulizer and a cyclonic spray chamber, operating at nebulizer gas flow rates of $15 \mathrm{~L} \mathrm{~min}^{-1}$ (Ar, purity 5.0).

\section{$2.2-\mathrm{H}_{2} \mathrm{O}_{2}$ treatment of graphitized carbon}

To enhance particle support interaction, the graphitized carbons treated in $\mathrm{H}_{2} \mathrm{O}_{2}$. For this $50 \mathrm{mg}$ of GCB powder was mixed under vigorous stirring into $100 \mathrm{ml}$ of $33 \% \mathrm{H}_{2} \mathrm{O}_{2}$ solution using a closed vial. The suspension was then heated to $100{ }^{\circ} \mathrm{C}$ and kept at this same temperature under stirring for 2 days. Then the suspension was cooled down to room temperature and centrifuged at $4000 \mathrm{rpm}$ for 30 min to remove the remaining $\mathrm{H}_{2} \mathrm{O}_{2}$. Finally the treated $\mathrm{GCB} \mathrm{H}_{2} \mathrm{O}_{2}$ powder was rinsed twice with MilliQ water and then dried in an oven at $80^{\circ} \mathrm{C}$ over night.

\section{3 - Electrochemical measurements}

The electrochemical measurements were performed in a homemade all-Teflon three compartment cell $[30,31]$. A carbon rod has been used as a counter electrode (CE), a home build multi-electrode with eight glassy carbon tips served as working electrodes (WE). The potential was controlled using a potentiostat (Princeton Applied Research, model 263A) in a three electrode setup. The reference electrode (RE) was a Schott standard calomel electrode (SCE) placed in a compartment separated by a membrane (Nafion $\left.{ }^{\circledR}\right)$ in order to avoid the diffusion of $\mathrm{Cl}^{-}$ions into the main compartment [32]. All potentials however are referred to the reversible hydrogen electrode (RHE) which was experimentally determined for each measurement series. The electrolyte was prepared using 


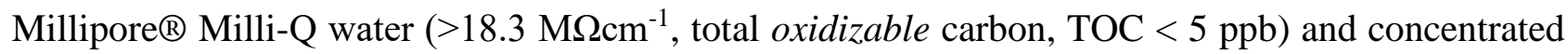
$\mathrm{HClO}_{4}$ (Suprapure;Merck Germany). Catalyst inks were prepared by ultrasonically dispersing the catalyst powder for at least $15 \mathrm{~min}$ in ultra-pure water. Then $20 \mathrm{ml}$ of the catalyst ink was pipetted onto each glassy carbon electrode leading to a Pt loading of $14 \mu \mathrm{g}_{\mathrm{Pt}} \mathrm{cm}^{-2}$ and thereafter dried in a nitrogen gas stream. Care should be taken that the catalyst ink is not heated from the ultrasonic bath, to avoid errors from changing water density. The measurements were performed in de-aerated electrolyte. The electrochemical surface area (ECSA) of the catalysts was determined from the CO stripping charge. In each CO-stripping experiment, carbon monoxide was adsorbed at $0.05 \mathrm{~V}_{\mathrm{RHE}}$ until saturation. Afterwards the electrolyte was purged with Ar for 10 min holding the potential. Finally, $\mathrm{CO}$ was electrochemically oxidized by scanning the potential from 0.05 to1.2 $\mathrm{V}_{\mathrm{RHE}}$ with a scan rate of $50 \mathrm{mV} \mathrm{s}^{-1}$. All the measurements were performed at room temperature and without rotation.

\section{4 - Accelerated stress test (AST) protocol}

The degradation behavior of the catalysts was evaluated employing an accelerated stress test treatment (AST) proposed by FCCJ consisting in potential cycles between 1-1.5 $\mathrm{V}_{\mathrm{RHE}}$ with a sweep rate of $500 \mathrm{mV} \mathrm{s}^{-1}$ [22]. This treatment simulates the potentials experienced in a fuel cell during start up and shut down. The treatment consisted in 27000 potential cycles (15h) and the ECSA was recorded every 3000 cycles up to 9000 cycles and then at 18000 and 27000 cycles. All the measurements were conducted at room temperature in $\mathrm{Ar}$ saturated $0.1 \mathrm{M} \mathrm{HClO}_{4}$ and without rotation. For a more detailed description of the AST treatment see Ref.[22]

\section{5 - Transmission electron microscope (TEM) Imaging}

For TEM investigations the catalyst dispersion was diluted by a factor of 1:10. The diluted dispersion was then sonicated for 10 minutes. Afterwards $5 \mu \mathrm{L}$ of the catalyst dispersion were pipette onto a copper grid (400 mesh; Plano, Germany) coated with a carbon film. In order to keep 
the catalyst loading low, after a few seconds the drop was adsorbed off the grid with a tissue. The grid was then dried and the catalyst investigated in a Tecnai T-20 G2 s-TEM (FEI) with an accelerating voltage of $200 \mathrm{kV}$.

\section{6 - Micro-Raman spectroscopy}

For the micro-Raman measurements, a drop of the sample was placed on a cleaned glass cover slip on an Olympus IX71 microscope and the sample was left to dry before measuring. A $514 \mathrm{~nm} \mathrm{CW}$ Argon Ion laser (CVI Melles Griot 35MAP431-200) was aligned into the microscope. Two narrow bandpass filter centered at 510 and 514 nm (Semrock FF02-510/20-25 and FF01-514/3-25) were used to spectrally clean the laser source. The laser light was reflected in the microscope on a 70/30 beam splitter (XF122 from Omega Filters) towards a 100X 1.3 NA immersion oil objective (Olympus UplanFL N) that focused the laser on the sample and collected the Raman signal. The power of the laser focused into a diffraction limited spot at the sample was $350 \mu \mathrm{W}, 120 \mu \mathrm{W}$ and $600 \mu \mathrm{W}$ for Figure 2, Figure 3A-B and Figure 3C-D, respectively. For Figure 2 and Figure 3A-B, a $514 \mathrm{~nm}$ longpass filter (Semrock LP02-514RE-25) was used to block the $514 \mathrm{~nm}$ laser light in the detection path. For Figure 3C-D an additional 514 nm longpass filter was present (Semrock LP02514RE-25 + Semrock LP02-514RU-25). The Raman spectrum was recorded by using a PI Acton

Spectra Pro SP-2356 polychromator $\left(600 \mathrm{~g} \mathrm{~mm}^{-1}\right.$ blazed at $\left.500 \mathrm{~nm}\right)$ and a PI Acton SPEC10:100B/LN eXcelon Spectroscopy System with a back-illuminated CCD chip $(1340 \times 100$ pixels $)$. $\mathrm{X}$-axis calibration of the spectra was performed after the measurements using a toluene Raman spectrum and/or a Neon pencil calibration lamp (ORIEL instruments, 6032 neon lamp). No further modifications or corrections were performed on the spectra. The data in Figure 3A-B was previously presented [7].

\section{7 - Brunauer-Emmett-Teller (BET) analysis}

Gas (nitrogen) adsorption isotherms were recorded using a Quantachrome Autosorb-1 Sorption 
Analyser in the relative pressure range $10^{-6}$ to $0.995 \mathrm{P} / \mathrm{P}_{0}$ at liquid nitrogen temperature $(77 \mathrm{~K})$. Prior to experiments, the samples were degassed by heating to $200^{\circ} \mathrm{C}$ in vacuum $\left(<10^{-3}\right.$ torr $)$ for 24 hours. The surface area was determined in the relative pressure range $0.05<\mathrm{P} / \mathrm{P}_{0}<0.3$ using the BET equation [33]. For all samples the BET plots were linear in the relative pressure range examined and the BET constant $>50$ confirming the applicability of the BET equation. Pore volumes estimated using t-plots [34].

\section{Results and discussion}

As discussed above, the main aim of the work was to systematically study the degradation of $\mathrm{Pt}$ NPs attached to different carbon supports, i.e. Vulcan $\mathrm{XC72R}$ as standard $\mathrm{CB}, \mathrm{GCB}$, and GCB treated in $\mathrm{H}_{2} \mathrm{O}_{2}\left(\mathrm{GCB} \mathrm{H}_{2} \mathrm{O}_{2}\right)$. As a first step the different carbon supports were characterized by a standard BET analysis. The results are displayed in Table 1. It is seen that all carbons have a relative low surface area, i.e. between $130 \mathrm{~m}^{2} \mathrm{~g}^{-1}$ for the GCB and $222 \mathrm{~m}^{2} \mathrm{~g}^{-1}$ for the Vulcan support. Interestingly, the $\mathrm{H}_{2} \mathrm{O}_{2}$ treatment increases the BET area of the GCB to a very similar value as obtained for Vulcan, i.e. $208 \mathrm{~m}^{2} \mathrm{~g}^{-1}$. The main difference of the GCBs, however is their lack of micropores below $2 \mathrm{~nm}$, which is independent of the $\mathrm{H}_{2} \mathrm{O}_{2}$ treatment.

$$
\text { BET total surface area, } \mathrm{m}^{2} \mathrm{~g}^{-1}
$$

Micropore surface area

$$
<2 \mathrm{~nm}, \mathrm{~m}^{2} \mathrm{~g}^{-1}
$$

\section{Vulcan XC72R (taken from [35])}

Graphitized carbon black

$\mathrm{H}_{2} \mathrm{O}_{2}$ treated graphitized carbon black

\section{2}

131

208

\section{8}

0

0

Table 1. Different carbon supports and their experimentally determined BET-surface area properties. 
The different properties of the carbon also become apparent when trying to attach Pt NPs to them. On Vulcan an even distribution of anchor sites exists and hence the Pt NPs are nicely distributed on the Vulcan support, see Figure 1a. By comparison the particle attachment to the GCB is severely inhibited due to the lack of defect sites. Our efforts to prepare a $30 \mathrm{wt} \%$ catalyst on the graphitized support resulted in highly agglomerated particles. Only reducing the nominal loading to $10 \mathrm{wt} \%$ resulted in somewhat un-agglomerated Pt NPs, see Figure 1b. In the TEM micrograph the uneven particle distribution on the GCB support is clearly discernible. It seems that the nanoparticles preferential attach to the darker, presumably graphitic planes. But in a 2 dimensional image of a 3 dimensional catalyst, this is difficult to judge. $\mathrm{H}_{2} \mathrm{O}_{2}$ treatment in turn improves particle dispersion on the support. For both catalysts the measured and nominal Pt weight loading deviates by 3-12\%, i.e. the attachment is similar; but ECSA values determined from CO stripping (Fig. 5) and calculated based on the Pt content determined by ICP-MS are significantly different. While for $\mathrm{Pt} /$ Vulcan an ECSA of $126 \mathrm{~m}^{2} \mathrm{gPt}^{-1}$ is determined, the obtained values of Pt/GCB and Pt/GCB $\mathrm{H}_{2} \mathrm{O}_{2}$ are 57 and $84 \mathrm{~m}^{2} \mathrm{gPt}^{-1}$, respectively. That is, the $\mathrm{H}_{2} \mathrm{O}_{2}$ treatment improves the ECSA by roughly $50 \%$ (please notice that for all catalysts the same Pt NP colloidal suspension was used).

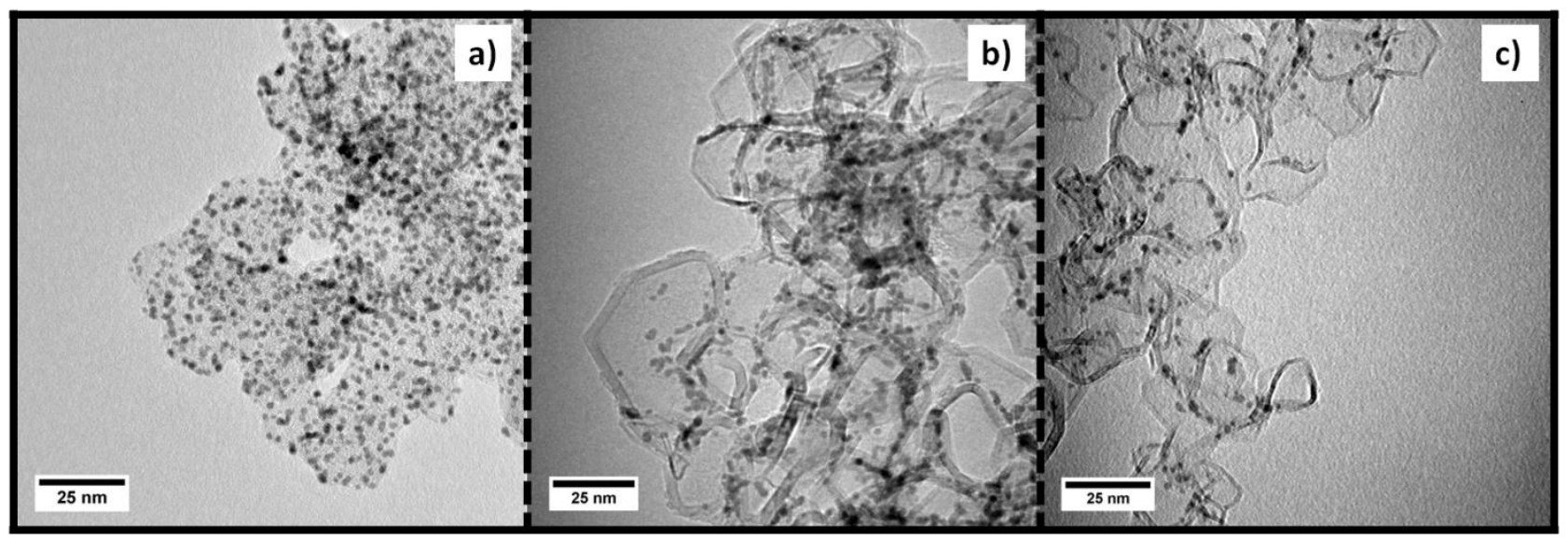

Figure 1. TEM micrographs of the synthesized Pt/C catalysts. a) $30 \mathrm{wt} \% \mathrm{Pt} / \mathrm{Vulcan}$, b) $10 \mathrm{wt} \% \mathrm{Pt} / \mathrm{GCB}$, c) 10 wt. $\%$ Pt/GCB $\mathrm{H}_{2} \mathrm{O}_{2}$. 
In the next step we investigated the influence of the $\mathrm{H}_{2} \mathrm{O}_{2}$ treatment on the GCB as well as the influence of AST treatments on the different catalysts using micro-Raman spectroscopy. In Figure 2 the Raman spectra of the bare graphitized carbon blacks (GCB) are shown before and after $\mathrm{H}_{2} \mathrm{O}_{2}$ treatment. The Raman spectra consist of two well defined, sharp peaks without any significant shoulder: a $\mathrm{G}$ (graphitic) and a D (disorder) band centred at ca. $1600 \mathrm{~cm}^{-1}$ and ca. $1350 \mathrm{~cm}^{-1}$, respectively. The ratio between $\mathrm{D}$ and $\mathrm{G}$ band intensity can be used of an indication of graphitic character of the CB. As a result of the $\mathrm{H}_{2} \mathrm{O}_{2}$ treatment the $\mathrm{I}_{\mathrm{D}} / \mathrm{I}_{\mathrm{G}}$ ratio increases (from 0.23 to 0.32 ), which could indicate an increase in the number of defects after the $\mathrm{H}_{2} \mathrm{O}_{2}$ treatment.

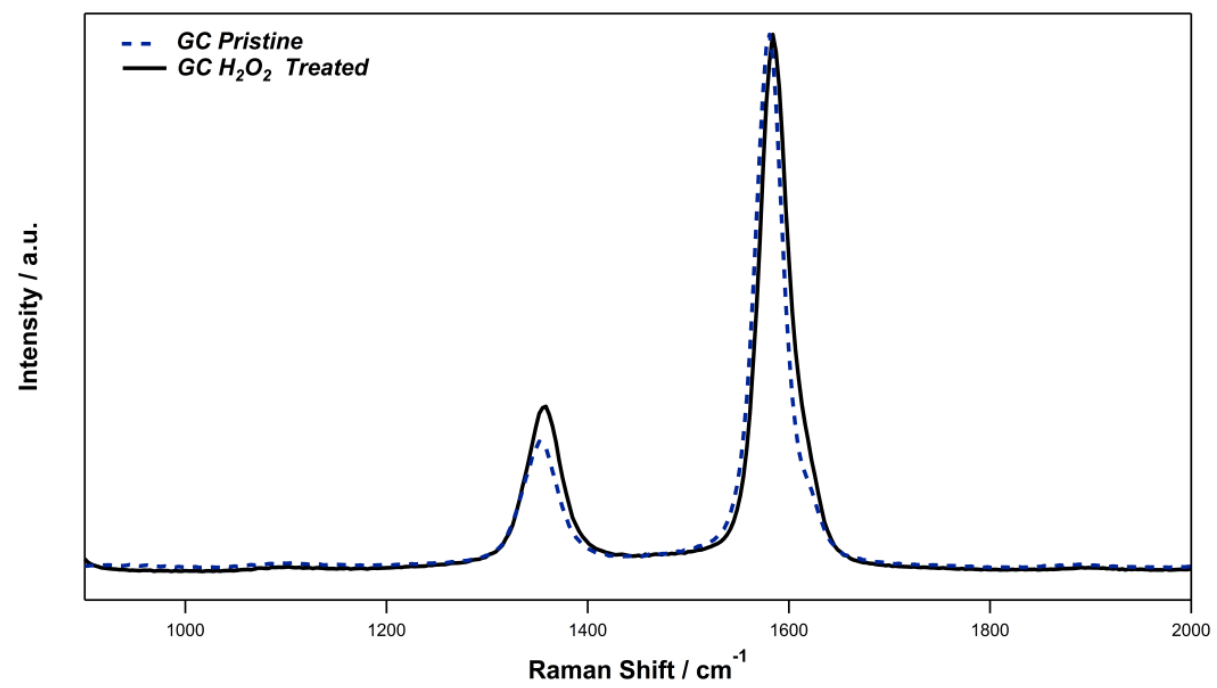

Figure2. Raman spectra of the pristine GCB and after $\mathrm{H}_{2} \mathrm{O}_{2}$ treatment. Each spectrum is the average of spectra recorded at 3 different spots. The spectra are normalized to the $\mathrm{G}$ peak.

In Figure 3, the influence of the AST treatment on the carbon supports of the catalysts is summarized. The Raman spectrum of the Pt/Vulcan catalyst at BOT (Figure 3a) is typical for an amorphous $\mathrm{CB}$ [36-38]. By comparing the $\mathrm{I}_{\mathrm{D}} / \mathrm{I}_{\mathrm{G}}$ ratio of the $\mathrm{Pt} / \mathrm{Vulcan}$ catalyst to the one of the Pt/GCB or Pt/GCB $\mathrm{H}_{2} \mathrm{O}_{2}$ catalyst, see Figure 3c and Table 2 (as the Raman spectra of the Pt/GCB and the Pt/GCB $\mathrm{H}_{2} \mathrm{O}_{2}$ catalyst are very similar, only the latter is shown in Figure 3 ), it can be seen that Vulcan is significantly more defected than the GCBs. Furthermore, in contrast to the GCBs the D band of Vulcan exhibits a shoulder towards lower wave numbers, which we didn't analyse further. 
The Raman spectrum of Pt/GCB $\mathrm{H}_{2} \mathrm{O}_{2}$ is similar to the one of the bare (without Pt NPs) support. The $\mathrm{I}_{\mathrm{D}} / \mathrm{I}_{\mathrm{G}}$ ratio is less than half the value as for the Pt/Vulcan catalysts, i.e. 0.51 as compared to 1.27; but, significantly larger than the bare $\mathrm{GCB} \mathrm{H}_{2} \mathrm{O}_{2}$ (see above). The first observation clearly demonstrates the highly graphitic character of the GCB. The second is contrary to what we observed on standard carbon black [7]. It seems that either the catalyst preparation procedure induces some defects on the GCB support or that a significant amount on graphitic sites is covered by the Pt NPs. A similar observation is reported in ref. [36]. Independent of the interpretation, the difference in defected carbon between the final catalysts Pt/GCB and Pt/GCB $\mathrm{H}_{2} \mathrm{O}_{2}$, is relative small; the $\mathrm{I}_{\mathrm{D}} / \mathrm{I}_{\mathrm{G}}$ ratio is 0.51 and 0.56 , respectively.
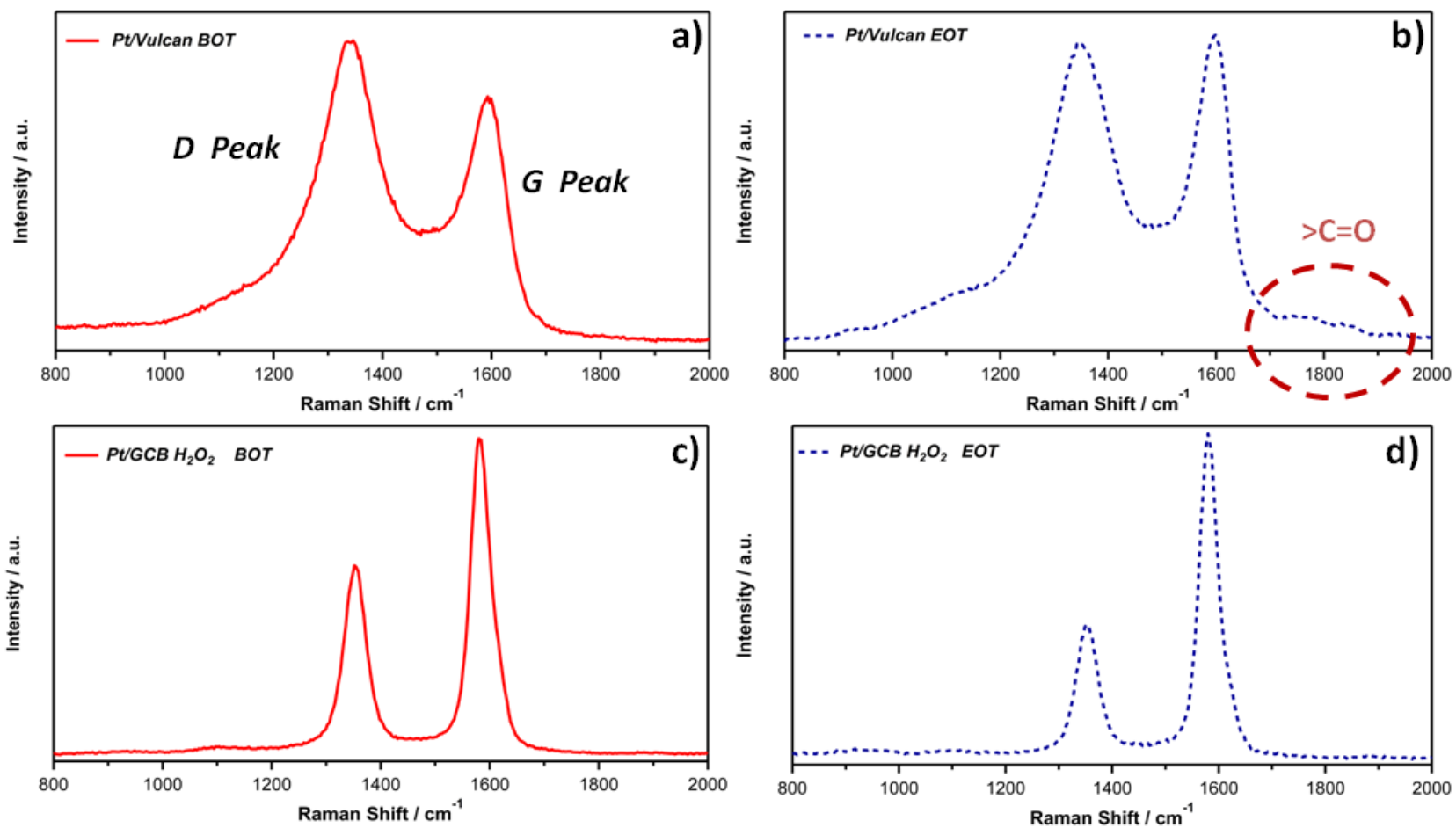

Figure 3. Raman spectra $30 \mathrm{wt} . \% \mathrm{Pt} / \mathrm{Vulcan}$ BOT treated at the beginning of the AST treatment (BOT) (a) (taken from [7]) and at the end of the AST treatment (EOT) (b). Raman spectra $10 \mathrm{wt} . \% \mathrm{Pt} / \mathrm{GCBs}_{2} \mathrm{O}_{2}$ (c)

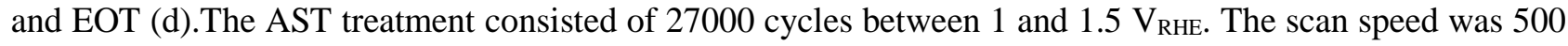
$\mathrm{mV} \mathrm{s}^{-1}$. 


$\begin{array}{lcc}\text { Pt/Vulcan } & 1.27 & 0.97 \\ \mathrm{Pt} / \mathrm{GCB} & 0.51 & 0.4 \\ \mathrm{Pt} / \mathrm{GCBH}_{2} \mathrm{O}_{2} & 0.56 & 0.51\end{array}$

Table 2. Relative maximum intensity ratios of the $D$ and $G$ peak $\left(I_{D} / I_{G}\right)$ of the different catalyst samples determined from the micro Raman spectra. $\mathrm{I}_{\mathrm{D}} / \mathrm{I}_{\mathrm{G}}$ is determined at the beginning the AST treatment (BOT) and at the end of the AST treatment (EOT). The given values are averaged from three different spots for each sample. The AST treatment consisted of 27000 cycles between 1 and $1.5 \mathrm{~V}_{\text {RHE. The scan speed was } 500 \mathrm{mV}}$ $\mathrm{s}^{-1}$.

The applied AST treatment has a similar effect on the three investigated catalysts. At EOT the intensity of the D peak associated with defective carbon is reduced in relation to the $\mathrm{G}$ peak. This observation is in contrary to results reported in ref. [36], where in MEA tests the intensity ratio of D and G peak stayed constant upon applying an AST treatment. The finding could indicate that the under our experimental conditions the AST treatment removes defective carbon sites from the carbon support surface instead of creating new ones [7]. Analyzing the relative change of the $\mathrm{I}_{\mathrm{D}} / \mathrm{I}_{\mathrm{G}}$ ratio, it is seen that for $\mathrm{Pt} / \mathrm{Vulcan}$ and $\mathrm{Pt} / \mathrm{GCB}$ a relative decrease of more than $20 \%$ is obtained, whereas in the case of $\mathrm{Pt} / \mathrm{GCB} \mathrm{H}_{2} \mathrm{O}_{2}$ a relative change of less than $10 \%$ is detected. However, the most significant between Vulcan and the GCBs is the oxidation of the Vulcan support indicated by the formation of an additional peak at around $1800 \mathrm{~cm}^{-1}$, which can be assigned to the $\mathrm{C}=\mathrm{O}$ stretch [7].

The difference in electrochemical stability between Vulcan and the GCBs is even more pronounced in the electrochemical signature. $\mathrm{CVs}$ recorded in $0.1 \mathrm{M} \mathrm{HClO}_{4}$ at $\mathrm{BOT}$ and EOT display a drastic change of the Pt/Vulcan catalyst due to the AST treatment, see Figure 4a. The $\mathrm{Pt} \mathrm{H}_{\text {upd }}$ region is significantly reduced at EOT. Furthermore a reversible peak assigned to hydroquinone/quinone emerges (at ca. $0.55 \mathrm{~V}_{\mathrm{RHE}}$ ) in addition to an increase of the double layer capacity of the carbon. As a result the typical $\mathrm{Pt} / \mathrm{C}$ type voltammogram changes to a rather undefined and featureless $\mathrm{CV}$. By comparison the changes in the $\mathrm{CV}$ of $\mathrm{Pt} / \mathrm{GCB}$ and $\mathrm{Pt} / \mathrm{GCB} \mathrm{H}_{2} \mathrm{O}_{2}$ inflicted by the AST are only 
minor; see Figure $4 \mathrm{~b}$ and $4 \mathrm{c}$ ). For Pt/GCB the double layer capacity stays almost constant and only minor changes are observed in the $\mathrm{H}_{\text {upd }}$ region. The adsorption of oxygenated species is slightly shifted to higher potentials. For Pt/GCB $\mathrm{H}_{2} \mathrm{O}_{2}$ change in the double layer seems somewhat more pronounced than for Pt/GCB, but else no significant differences are apparent.
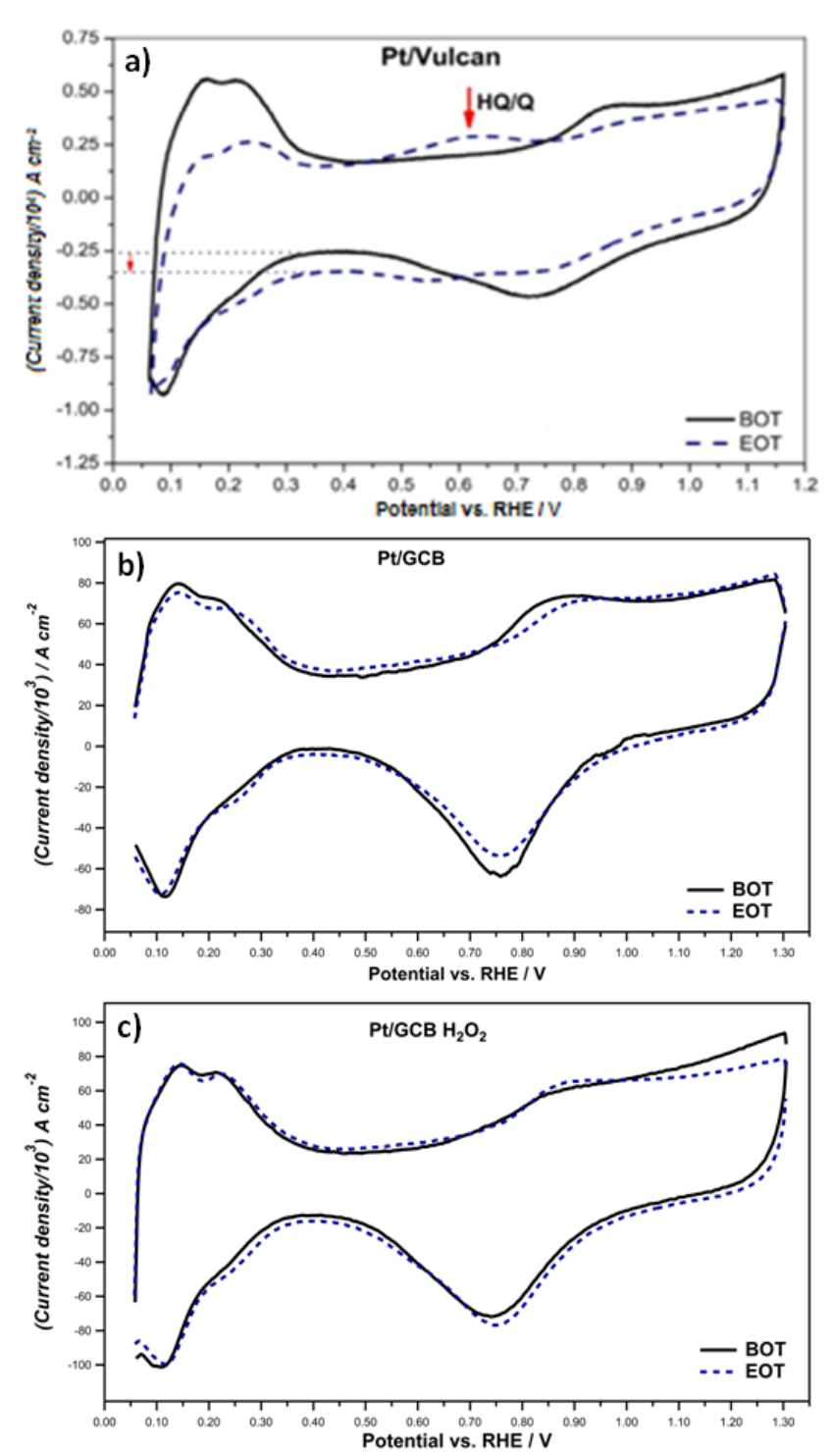

Figure 4. (a) Effect of AST treatment on the cyclic voltammograms of $30 \mathrm{wt} . \% \mathrm{Pt} / \mathrm{Vulcan}$ (taken from ref. [7]), (b) $10 \mathrm{wt} . \% \mathrm{Pt} / \mathrm{GCB}$ and (c) $10 \mathrm{wt} \% \mathrm{Pt} / \mathrm{GCB} \mathrm{H}_{2} \mathrm{O}_{2}$ treated The cyclic voltammograms were recorded in $0.1 \mathrm{M} \mathrm{HClO}_{4}$ with a sweep rate of $50 \mathrm{mV} \mathrm{s}^{-1}$. The AST treatment consisted of 27000 cycles between 1 and $1.5 \mathrm{~V}_{\text {RHE}}$. The scan speed was $500 \mathrm{mV} \mathrm{s}^{-1}$.

The change in the electrochemical signature of the CVs is in line with the catalyst stability probed by determining the ECSA via CO stripping recorded at BOT and at the EOT (i.e. after 27000 
potential cycles between $1-1.5 \mathrm{~V}_{\mathrm{RHE}} 500 \mathrm{mV} \mathrm{s}^{-1}$ ) for the three catalysts, see Figure 5a-c. It is apparent that the ECSA loss for Pt/Vulcan is significant larger than for Pt/GCB and Pt/GCB $\mathrm{H}_{2} \mathrm{O}_{2}$. Furthermore, all the catalysts display a pre-peak as a shoulder of the main peak at the EOT. Such a pre-peak is often associated to Pt NP agglomeration [39].

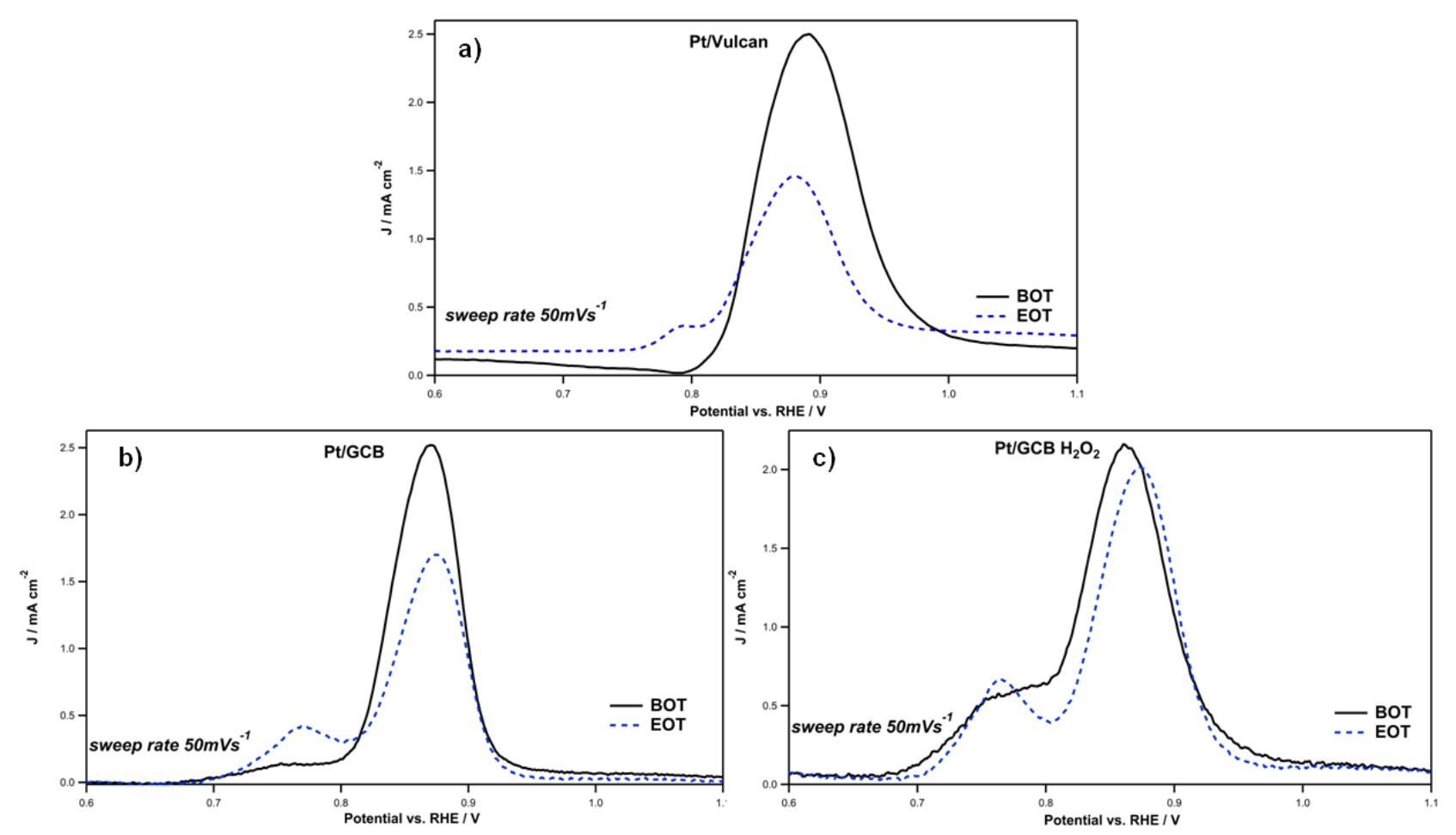

Figure 5. CO stripping curves at BOT (solid black line) and EOT (dotted blue line). a) Pt/Vulcan, b) Pt/GCB and c) $\mathrm{Pt} / \mathrm{GCB} \mathrm{H}_{2} \mathrm{O}_{2}$ treated.

In order to obtain a good statistic of the electrochemical stability of the different catalysts, the AST treatment has been repeated several times for each catalyst. In Figure 6 the electrochemical stability of the different catalysts is summarized in a plot comparing the normalized ECSA loss as a function of the number of potential cycles between 1 and $1.5 \mathrm{~V}_{\text {RHE. }}$ In this plot the difference between $\mathrm{Pt} /$ Vulcan and the Pt/GCB catalysts is highlighted, but it is also seen that the $\mathrm{H}_{2} \mathrm{O}_{2}$ treatment leads to a significant increase in electrochemical stability under the applied conditions. We can conclude the following stability trend: $\mathrm{Pt} / \mathrm{GCB} \mathrm{H}_{2} \mathrm{O}_{2}>\mathrm{Pt} / \mathrm{GCB}>\mathrm{Pt} / \mathrm{Vulcan}$. While Pt/Vulcan loses $33 \%$ of its ECSA after 27000 cycles, Pt/GCB loses $17 \%$ and $\mathrm{Pt} / \mathrm{GCB} \mathrm{H}_{2} \mathrm{O}_{2}$ only $8 \%$. In addition to the significantly reduced relative ECSA loss, also differences in the trend of ECSA loss with increasing 
AST cycles become apparent. For the standard Pt/Vulcan catalyst most of the ECSA loss occurs in the first 10000 cycles, thereafter the rate of ECSA loss per cycle decreases. By comparison for the two Pt/GCB catalysts a rather constant ECSA loss per cycle is observed. Beside the improved carbon stability of GCB as indicated by Raman, the larger initial degradation of Pt/Vulcan might be in part related to its higher Pt wt.\% (related to its BET surface area). A higher Pt loading leads to a reduced interparticle distance, which should favor particle agglomeration.

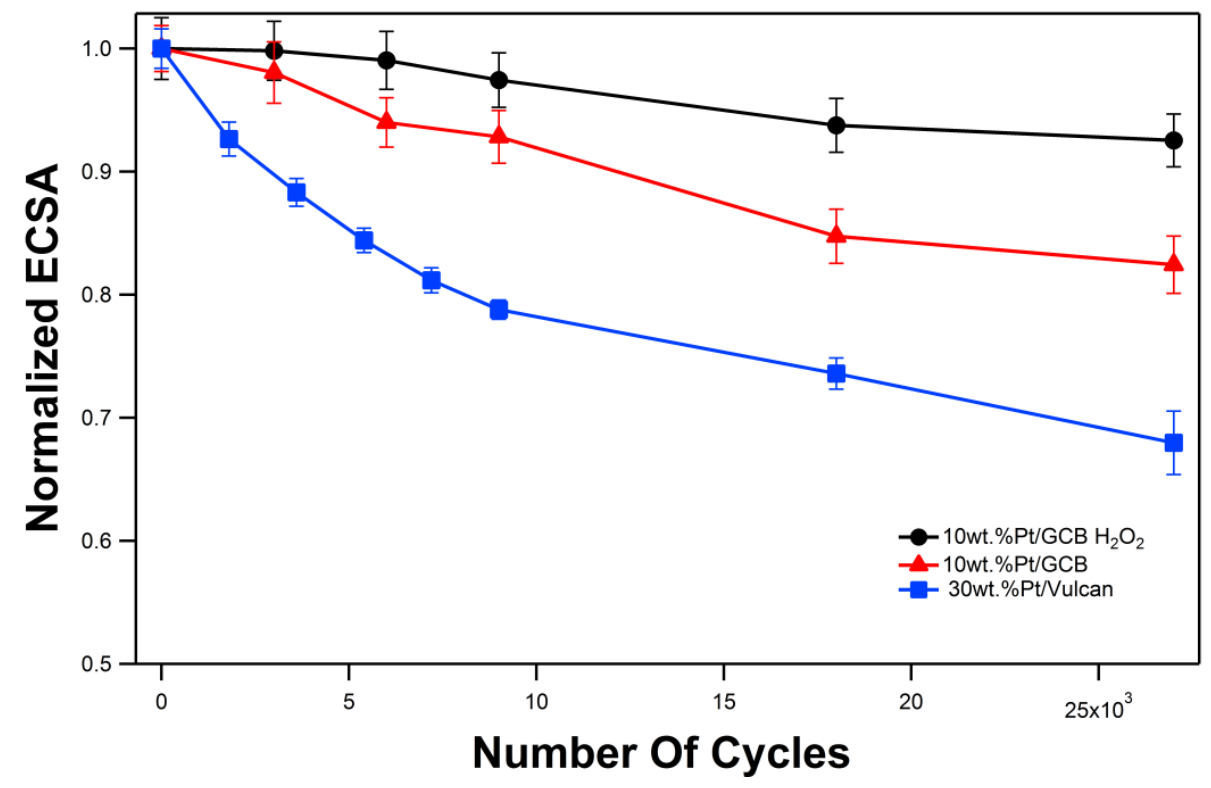

Figure 6. Comparison of the normalized ECSA as a function of the number of potential cycles during the AST. The ECSA was determined by CO stripping. $30 \mathrm{wt} . \% \mathrm{Pt} / \mathrm{Vulcan}$ blue squared line (taken from [7]), 10 wt. $\% \mathrm{Pt} / \mathrm{GCB}$ red triangular line and $10 \mathrm{wt} . \% \mathrm{Pt} / \mathrm{GCB} \mathrm{H}_{2} \mathrm{O}_{2}$ black dotted line (the lines serve as guides for the eye). The AST treatment consisted of cycles between 1 and $1.5 \mathrm{~V}_{\text {RHE }}$ applying a scan speed of $500 \mathrm{mV} \mathrm{s}^{-1}$.

\section{Conclusion}

In the presented study we applied the tool-box approach for investigating graphitized carbon as support PEMFC catalysts. The approach enables us to examine the same Pt NPs linked to different supports, i.e. Vulcan, GCB, and GCB treated in hydrogen peroxide. The results clearly demonstrate advantages, but also the limits of GCBs as supports for PEMFC catalysts. The main advantage is the significant higher stability. Applying harsh AST test protocols aimed at degrading the support, 
the ECSA loss can be reduced to $25 \%$ of the value measured for Vulcan (for $\mathrm{GCB}_{2} \mathrm{O}_{2}$ ). Interestingly, especially the initial fast degradation is inhibited. The main limitation, however, is the low number of anchor sites for NPs on graphitized supports. For high power density applications, catalysts with high Pt loading (50 wt.\% or more) are needed. Mild etching improves catalyst stability, but further optimization of the procedure is needed to obtain highly loaded catalyst samples.

\section{Acknowledgment}

This work was supported by the Danish DFF through grant no.10-081337. We acknowledge Dipl.Ing. Andrea Mingers of the group of Dr. Karl J.J. Mayrhofer at the MPIE for the ICP-MS analysis as well as Dr. Denis Okhrimenko from the Department of Chemistry, University of Copenhagen, for the BET measurements. T.V. likes to thank the "Center for Synthetic Biology" at Copenhagen University funded by the UNIK research initiative of the Danish Ministry of Science, Technology and Innovation (Grant 09-065274) and bioSYNergy, University of Copenhagen's Excellence Programme for Interdisciplinary Research.

\section{References}

[1] Y. Wang, X. Wang, Solvent and Simple Ion-Stabilized Metal Nanoclusters: Chemical Synthesis and Application, in: B. Corain, G. Schmid, N. Toshima (Eds.) Metal Nanoclusters in Catalysis and Materials Science: The Issue of Size Control, Elsevier, 2008, pp. 327-340.

[2] Y. Wang, J.L. Zhang, X.D. Wang, J.W. Ren, B.J. Zuo, Y.Q. Tang, Topics in Catalysis, 35 (2005) 35-41.

[3] J. Speder, L. Altmann, M. Baumer, J.J.K. Kirkensgaard, K. Mortensen, M. Arenz, Rsc Advances, 4 (2014) 14971-14978.

[4] J. Speder, L. Altmann, M. Roefzaad, M. Bäumer, J.J. Kirkensgaard, K. Mortensen, M. Arenz, Physical Chemistry Chemical Physics, 15 (2013) 3602-3608.

[5] J. Speder, A. Zana, I. Spanos, J.J.K. Kirkensgaard, K. Mortensen, M. Arenz, Electrochemistry Communications, 34 (2013) 153-156.

[6] J. Speder, A. Zana, I. Spanos, J.J.K. Kirkensgaard, K. Mortensen, M. Hanzlik, M. Arenz, J Power Sources, 261 (2014) 14-22.

[7] A. Zana, J. Speder, N.E.A. Reeler, T. Vosch, M. Arenz, Electrochim Acta, 114 (2013) 455-461.

[8] A. Zana, J. Speder, M. Roefzaad, L. Altmann, M. Baumer, M. Arenz, Journal of the Electrochemical Society, 160 (2013) F608-F615. 
[9] Y. Wang, J.W. Ren, K. Deng, L.L. Gui, Y.Q. Tang, Chem Mater, 12 (2000) 1622-1627.

[10] R.M. Crooks, M.Q. Zhao, L. Sun, V. Chechik, L.K. Yeung, Accounts Chem. Res., 34 (2001) 181-190.

[11] F. Hasche, M. Oezaslan, P. Strasser, Chemcatchem, 3 (2011) 1805-1813.

[12] S. Koh, J. Leisch, M.F. Toney, P. Strasser, J. Phys. Chem. C, 111 (2007) 3744-3752.

[13] M. Oezaslan, M. Heggen, P. Strasser, Abstr Pap Am Chem S, 242 (2011).

[14] C. Baldizzone, S. Mezzavilla, H.W.P. Carvalho, J.C. Meier, A.K. Schuppert, M. Heggen, C. Galeano, J.D. Grunwaldt, F. Schuth, K.J.J. Mayrhofer, Angew Chem Int Edit, 53 (2014) 14250-14254.

[15] C. Baldizzone, S. Mezzavilla, N. Hodnik, A.R. Zeradjanin, A. Kostka, F. Schuth, K.J.J. Mayrhofer, Chem Commun, 51 (2015) 1226-1229.

[16] C. Galeano, C. Baldizzone, H. Bongard, B. Spliethoff, C. Weidenthaler, J.C. Meier, K.J.J. Mayrhofer, F. Schuth, Adv Funct Mater, 24 (2014) 220-232.

[17] H.A. Gasteiger, N.M. Marković, Science, 324 (2009) 48-49.

[18] M. Lefèvre, E. Proietti, F. Jaouen, J.-P. Dodelet, Science, 324 (2009) 71-74.

[19] M.K. Debe, Nature, 486 (2012) 43-51.

[20] P.J. Ferreira, G.J. la O, Y. Shao-Horn, D. Morgan, R. Makharia, S. Kocha, H.A. Gasteiger, Journal of the Electrochemical Society, 152 (2005) A2256-A2271.

[21] J.C. Meier, C. Galeano, I. Katsounaros, A.A. Topalov, A. Kostka, F. Schuth, K.J.J. Mayrhofer, ACS Catal., 2 (2012) 832-843.

[22] A. Ohma, K. Shinohara, A. liyama, T. Yoshida, A. Daimaru, ECS Transactions, 41 (2011) 775-784.

[23] L.M. Roen, C.H. Paik, T.D. Jarvic, Electrochem. Solid State Lett., 7 (2004) A19-A22.

[24] W. Bi, T.F. Fuller, Journal of The Electrochemical Society, 155 (2008) B215-B221.

[25] T.F. Fuller, G. Gray, ECS Transactions, 1 (2006) 345.

[26] E.L. Redmond, B.P. Setzler, P. Juhas, S.J.L. Billinge, T.F. Fuller, Electrochem. Solid State Lett., 15 (2012) B72-B74.

[27] A. Zana, C. Rudiger, J. Kunze-Liebhauser, G. Granozzi, N.E.A. Reeler, T. Vosch, J.J.K. Kirkensgaard, M. Arenz, Electrochim Acta, 139 (2014) 21-28.

[28] K. Kinoshita, Carbon: Electrochemical and Physicochemical Properties, Wiley, New York, 1988.

[29] I. Spanos, K. Dideriksen, J.J.K. Kirkensgaard, S. Jelavic, M. Arenz, Physical Chemistry Chemical Physics, 17 (2015) 28044-28053.

[30] K.J.J. Mayrhofer, A.S. Crampton, G.K.H. Wiberg, M. Arenz, Journal of the Electrochemical Society, 155 (2008) P78-P81.

[31] K.J.J. Mayrhofer, G.K.H. Wiberg, M. Arenz, Journal of the Electrochemical Society, 155 (2008) P1-P5.

[32] K.J.J. Mayrhofer, S.J. Ashton, J. Kreuzer, M. Arenz, International Journal of Electrochemical Science, 4 (2009) 1-8.

[33] S. Brunauer, P.H. Emmett, E. Teller, Adsorption of gases in multimolecular layers, in: Journal of the American Chemical Society, 1938, pp. 309-319.

[34] B.C. Lippens, J.H. de Boer, Journal of Catalysis, 4 (1965) 319-323.

[35] J. Speder, A. Zana, M. Arenz, Catalysis Today, 262 (2016) 82-89.

[36] M. Hara, M. Lee, C.H. Liu, B.H. Chen, Y. Yamashita, M. Uchida, H. Uchida, M. Watanabe, Electrochim Acta, 70 (2012) 171-181.

[37] A. Sadezky, H. Muckenhuber, H. Grothe, R. Niessner, U. Poschl, Carbon, 43 (2005) 1731-1742.

[38] T. Jawhari, A. Roid, J. Casado, Carbon, 33 (1995) 1561-1565.

[39] F. Maillard, S. Schreier, M. Hanzlik, E.R. Savinova, S. Weinkauf, U. Stimming, Physical Chemistry Chemical Physics, 7 (2005) 385-393. 